effect as the disease seemed to stop spontaneously. No idea can be formed as to how the patient became infected.

CASE 2.-The patient, Sergeant F. P., Eighth Band, C. A. C., first noticed small red pimple on middle of plantar surface, left foot, very itchy; from the pimple extended a small red line, serpentine in character; it seemed to extend about one inch in twenty-four hours. Two weeks later there was a similar condition on top of the fourth toe of the right foot, the line extending around the toe to the plantar surface of foot, running toward the heel for two and one-half inches, turning to the left about one and one-half inches, then doubling back on itself to the riglit aspect of foot. The patient could distinctly see and feel the progress of the parasite. The itching at night would keep the patient awake. These lines of eruption corresponded exactly to the description of creeping eruption as given by Hamburger in his article on the subject. Repeated examinations of small portions of skin and tissue failed to demonstrate the larvæ of the parasite, but in each instance stopped the progress of the disease at that point.

This case has been observed for about three weeks, and at present the eruption has practically disappeared. With the exception of a few scales along the line of the parasite's travel, the patient has entirely recovered. This case I believe to be specially interesting, because, so far as I am able to find out, it is the only case reported in which the eruption has occurred on two different parts of the patient at the same time.

Continuous observation on my part showed that this line increased about three-quarters of an inch in twenty-four hours. No idea can be formed as to how patient became infected.

\section{MODIFIED TECHNIC IN RESECTION OF THE RECTUM *}

J. RAWSON PENNINGTON, M.D.

Irofessor of Rectal Diseases, Chicago College of Medicine and surgery and the Chicago Policlinic

$$
\text { CHICACOO }
$$

The accompanying schematic drawing will serve to illustrate a method of resecting the rectum employed by myself and Dr. Gronnerud in a special case. The growth for which the technic was employed extended

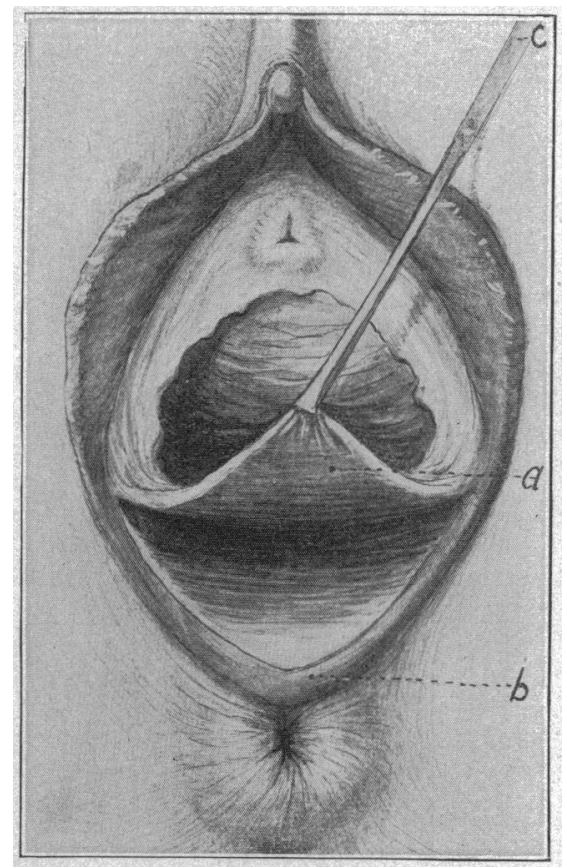

Fig. 1.-Mucocutaneous incision, corresponding to perineorrhaphy and extending from caruncle to caruncle, which was first made: also method of splitting the rectovaginal septum, $a$ and $b$, and of elevating the posterior vaginal flap, a.

This illustration and those following are by Dr. Zan D. Klopper.

* Read at the Eleventh Annual Meeting of the American Proctologic Society, Atlantic City, June, 1909.

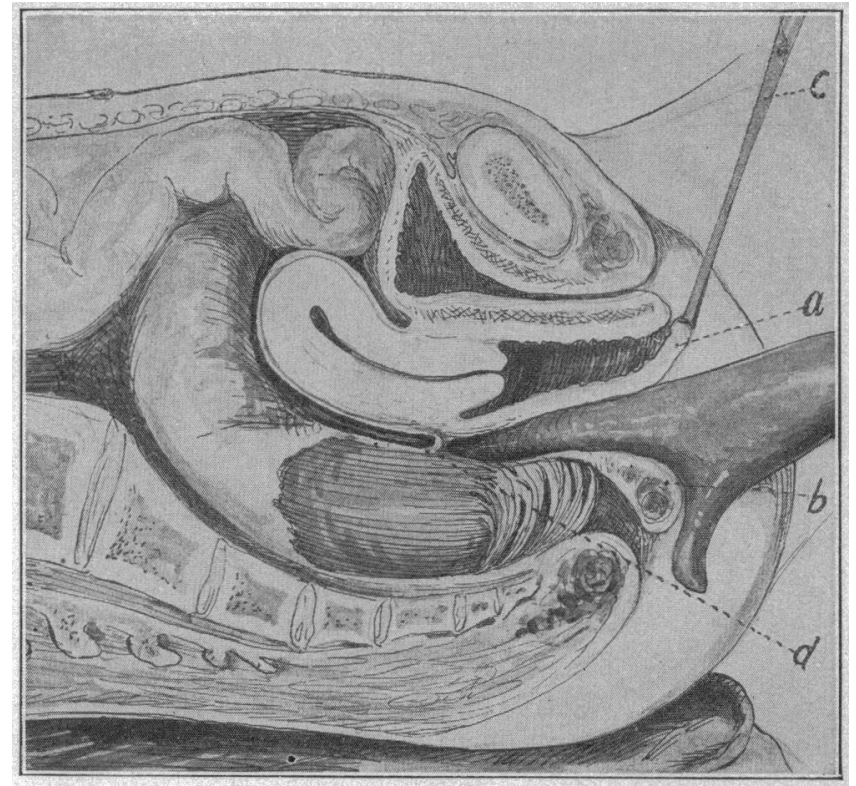

Fig. 2.-The rectovaginal septum, $a$ and $b$, has been divided, the flap, a, raised, the rectum exposed and the index-finger carried up through the divided septum to the peritoneal reflection, d.

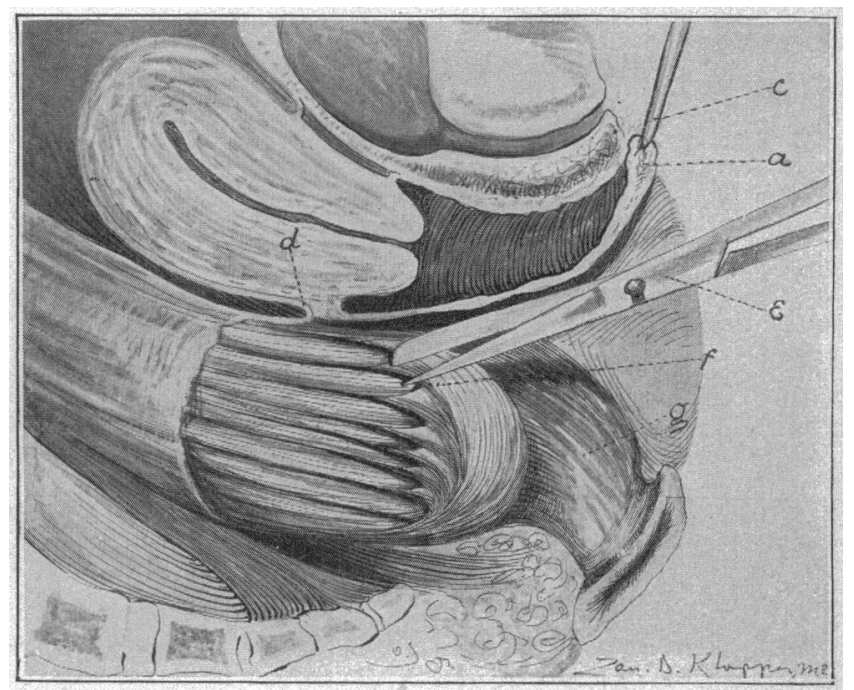

Fig. 3.-Dissecting fascia and levator ani muscle, $\mathrm{t}$, from rectum, g.

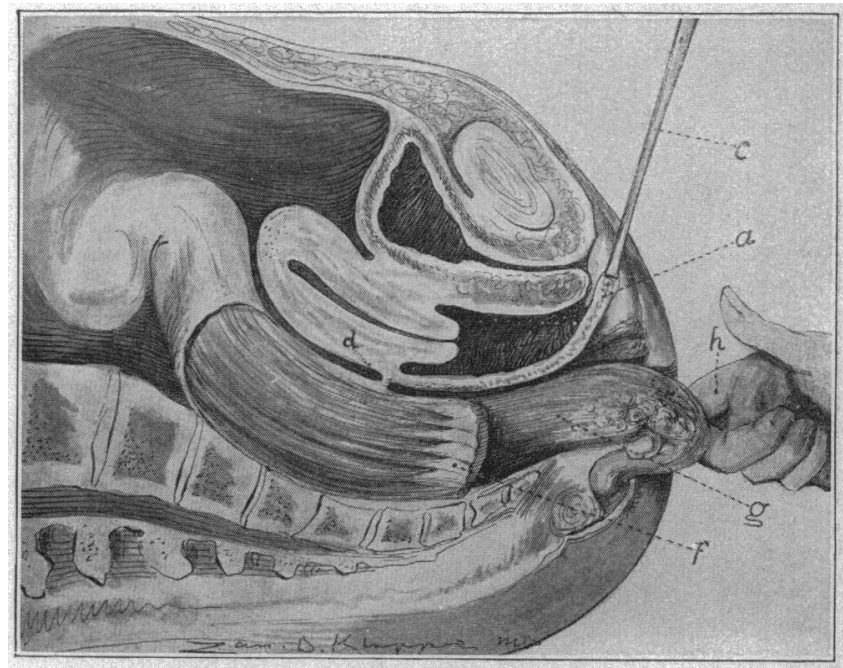

Fig. 4.-Lateral view. The rectum has peen dissected rom the cellular tissues, then pulled downward and outward with the finger, $h$, which has been passed between the rectum and coccyx. 'This exposes the tumor mass, $g$. 


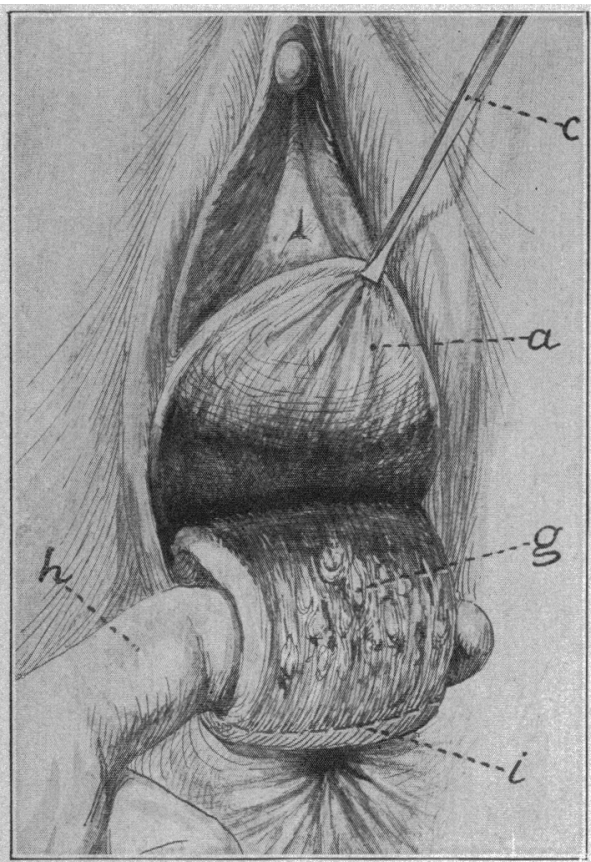

Fig. 5.-Front view of the same position as shown in Figure $4 ; i$, line for distal in. cision.

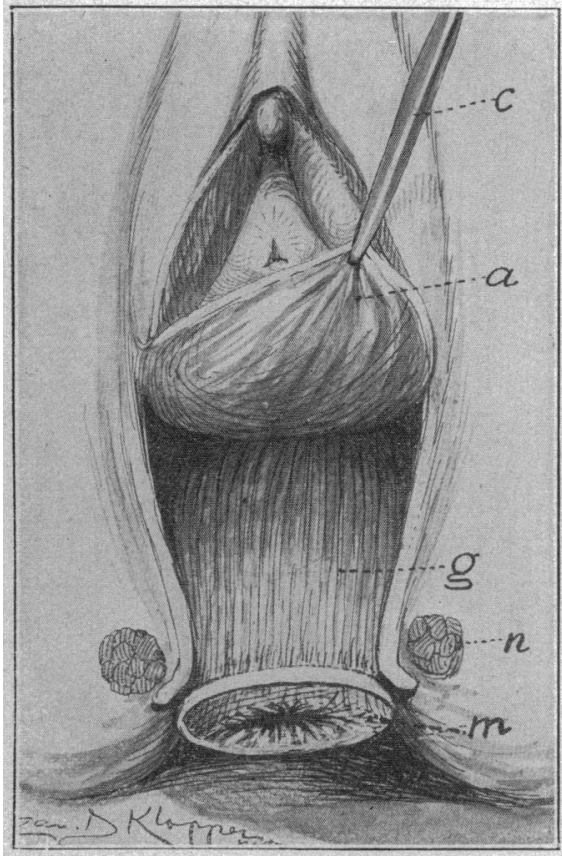

Fig. 8.-Rectum, g, adjusted in the divided anal canal preparatory to suturation.

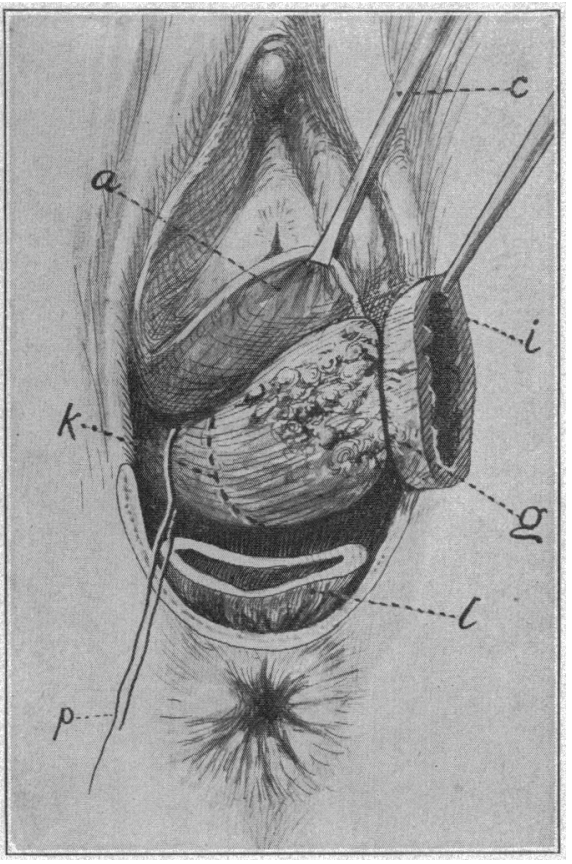

Fig. 6.-The distal incision has been made and the loosened end of the bowe] contaiuing the growth, g, elevated; 1 , is the anal canal; p, ligature for temporarily tying off the bowel; $k$, line for proximal incision.

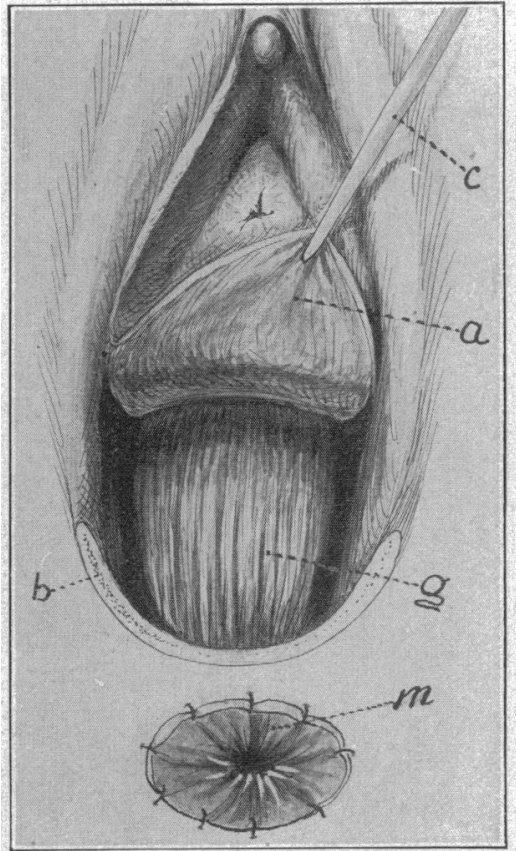

Fig. 9.-Rectum, g, being pulled through the everted and undivided canal and suthe everted and undivided canal and sutured externally at $m$, afte
retracts as shown in Figure 11.

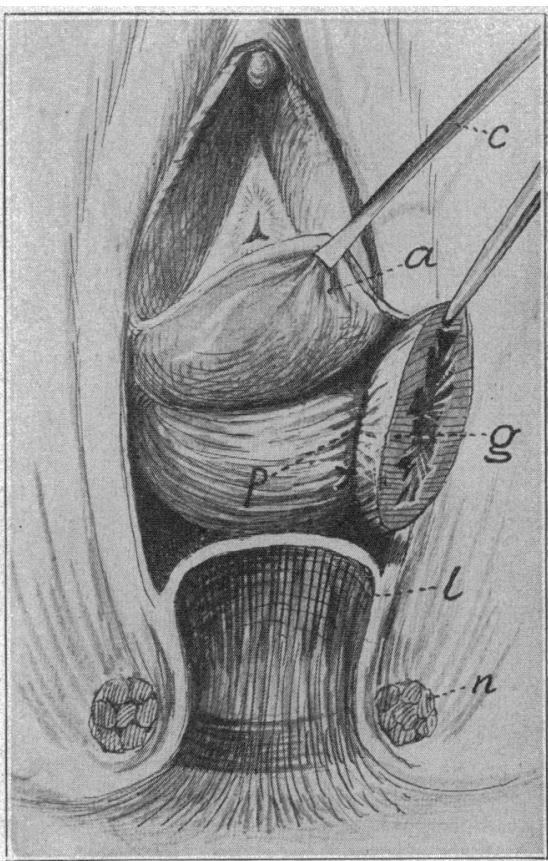

Fig. 7-In this cut the tape, p, bas been tied, the growth removed, and the sphinc ter, $n$, and the anal canal, 1. incised and laid open. 
upward from the proximal border of the levator ani muscle for about $21 / 2$ inches.

After removing the growth, as illustrated, we divided the anal canal and completed the operation as shown in Figures 7,8 and 10 . In some cases, however, I think it preferable to evert the anal canal, pull the upper part of the rectum or sigmoid, as the case may be, through this eversion and effect the end-to-end anastomosis on the outside and complete the operation as shown in Figures 9 and 11.

After the growth had been removed the incision was closed with buried catgut sutures and silkworm gut for

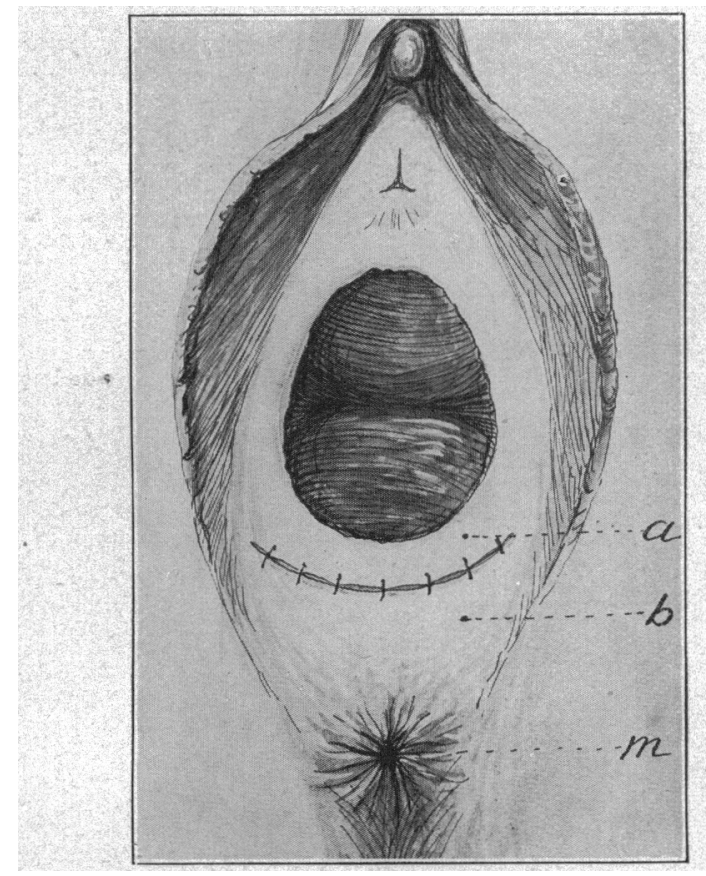

Fig. 11.-Line of suturing the rectovaginal septum in the completed operation when the anal canal has not been divided as shown in Figure?.

the sin. The posterior raginal flap, covering up, as it dirl, the field of operation, prevents the urine, vaginal and uterine serretions from coming in contact with the wound. Moreover, should it be found necessary, the reflection of peritoneum at $d$, in Figure 2 , could be divided and the operation extended into the abdomina! cavity.

The legends under the illustrations show the varions stens in the operation.

103 State Street.

\section{INTRACRANIAT, NEURECTOMY OF THE SU- PERTOR ANI) INFERIOR MAXIJIAARY NERVES FOR TIC DOULOUREIX}

\section{T. E. POTTER, M.D}

Professor of Irinciples and Practice of Surgers in Ensworth Med. ical College

ST. JOSEPII, MO

History.-H. L. B., aged 68 , applied for surgical treatment July 18. Patient gave a history of a most terrible tic douloureux of the left face and head from which he liad suffered the most intense pain for ten years. He said further that he had had periodic attacks for thirty-five years, but the continuous pain had been present for nine or ten years. Until five years ago the area supplied by the ophthalmic division of the fifth nerve had been the one most affected, especially the infraorbital branch, and he had submitted to an operation in Omaha, where this nerve was divided. This gave no relief, but rather intensified the pain in the area supplied by the supratrochlear and supraorbital branches of the first division and the superior and inferior maxillary divisions. While the patient was in the hospital for three days previous to the operation he showed slight symptoms of dementia, at times wandering about in a semicomatose condition. He had an extremely sensitive sore on the left side of his nose, which had been present for a long time. During this preoperative period of three days he had two epileptic attacks, to which he had been subject ever since the pain had become so intense. He could not bear the touch of the hand on any part of the area supplied by the nerve, although I noticed that he was not very sensitive in the area of the infraorbital nerve supply which, as stated above, had been eut. He complained also of grcat soreness of the gums, so sensitive that at times he could not close his mouth and he rarely ate anything but liquid diet. Shaving of the left face and head caused great pain. Some conjunctivitis was present.

Operation.-On the fourth day after admission I performed Cushing's operation for removing the Gasserian ganglion. Instead of clipping the zygoma with bone forceps as he sucrgests I used the Gigli-Haertel saw, first making two small grooves underneath the zygoma near the helix and malar bones with a sharp pointed probe and drawing the flexible blade through the opening with a curved forcep. This gave a most satisfactory severance of the arch and there was absolutely no deformity as aceompanying photographs (Figs. 1 and 2) show. Following the suggestion of Cushing and others I nipped away a small portion of the skull at the junction of the great wing of the sphenoid and the squamous portion of the temporal bone, with a chisel and in so doing ruptured the middle meningeal artery which lay very deeply embedded in the meningeal groove in the bone, being; more superficial than I had anticipated. After enlarging the opening to about $1 \frac{1 / 2}{2}$ inches $I$ tied the ruptured meningeal and was bothered with no more hemo"rhage from this source. 1 want to emphasize the necessity of clipping the opening in the bone to include the crista infratemporalis and thus give

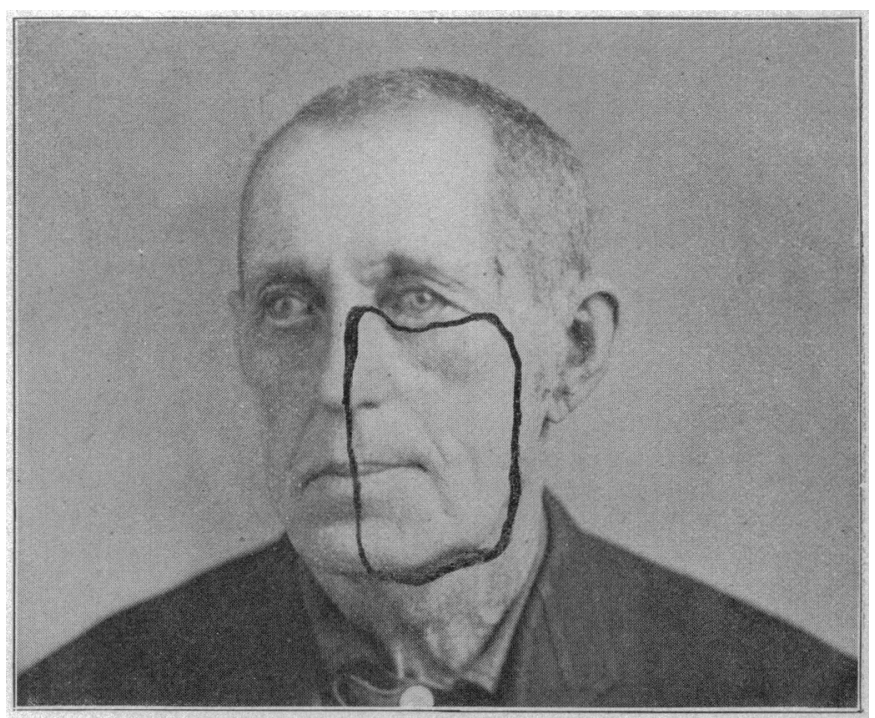

Fig. 1.-Neurectomy in tic douloureux; area of total surgical anesthesia at end of fourth week after operation.

a much clearer field for operative procedure; the lower the lyone incision the better. After tying the artery $T$ raised the temporal lobe with a flexible retractor about $l$ inch in wirlth and explored the cavity. Few of the accounts mention the almost absolute necessity of using a head light and many operators making the operation for the first time are apt to omit this most important detail. As all of the literature states, the hemorrhage is most annoying. Everything in the cavity bleeds. I tamped the bleeding points with very small sponges attached to the ends of straight forceps with little effect on the hemorrhage. I found that by pack- 